DOI: $10.17805 /$ zpu.2019.1.4

\title{
Образы современности в XXI веке: сверхмодернизм
}

\author{
A. В. ПАВЛОВ \\ ИнСтИтУт ФИЛОСОФИИ РАН
}

Начиная с 1990-х годов многие социальные теоретики, культурологи и философы стали говорить об угасании или даже смерти постмодернизма не столько как философского течения, сколько как исторического периода. К 2000 г. на этот счет сложился консенсус, который озвучила литературовед и лидер в исследованиях постмодерна Л. Хатчеон, объявив открытым конкурс на различные концепции постпостмодернизма. Настоящая статья посвящена одной из самых ранних альтернатив постмодернизму - сверхмодернизму возникновению (теория французского антрополога М. Оже) и развитию концепции и самого термина у других авторов (таких как нидерландский историк архитектуры Г. Ибелингс и испанский «археолог современности» А. Гонзалес-Руибал).

Автор объясняет, почему русский перевод термина «supermodern" как «гипермодерн» в высшей степени некорректный, излагает суть теории Оже (в частности, его идею «трех избытков» сверхмодерна - времени, пространства и индивидуальных референций). Также сравниваются подходы М. Оже и тех мыслителей, которые приняли концепцию «сверхмодерна», попытавшись применить в иных областях - архитектуре и «археологии современности». Наконец, автор критически анализирует концепцию, пытаясь обнаружить ее эвристический потенциал. Он заключает, что идея сверхмодерна в настоящий момент не 
выдерживает критики. История доказала, что интуиции Оже, пусть и «предварительные», себя не оправдали в социальном, культурном и антропологическом отношении. Также автор текста сравнивает концепцию сверхмодерна с постмодерном, доказывая, что многое из того, что приписывается сверхмодерну, на самом деле имманентно содержится в теориях постмодерна, в частности в философии культуры американского марксиста Фредрика Джеймисона.

Ключевые слова: постмодерн; постпостмодерн; сверхмодерн; социальная философия; культура; марксизм; гипермодерн; антропология; М. Оже

\section{ВВЕАЕНИЕ}

$\Pi$ осле того как $\Lambda$. Хатчеон, канадская исследовательница литературы и одна из главных теоретиков постмодерна, первой в 2002 г. во всеуслышание заявила о том, что эпоха постмодерна завершилась, и объявила в эпилоге второго издания своей книги «Политика постмодернизма» конкурс на то, чтобы следующее поколение исследователей занялось поиском нового языка описания актуального для нас времени: «Пост-постмодернизм нуждается в новом собственном ярлыке, и я подвожу итог: бросаю вызов читателям самостоятельно найти его и дать ему имя собственное в двадцать первом веке» (Hutcheon, 2002: 181), гуманитарии разной направленности - от культурологов и литературоведов до социальных теоретиков и антропологов - начали предлагать собственные версии современности (модерна). Так, появились следующие концепции, объявившие о смерти постмодерна и претендующие на то, чтобы занять его место в качестве «ярлыка» очередного исторического периода: диджимодерн, автомодерн, метамодерн, космодерн, альтермодерн, гипермодерн и многие другие.

Эти теории были названы зонтичным термином «постпостмодернизм» и почти все были собраны в антологии, вышедшей в 2015 г. (Supplanting the Postmodern ..., 2015). Однако в книге представлены отнюдь не все версии постпостмодернизма. Например, существует концепция «неомодерна», озвученная, что характерно, отечественным ученым и обращенная исключительно к Востоку, а не Западу. Правда, этот термин в совсем другом контексте появился еще в 1994 г. и, таким образом, оказался давно занят (Кузнецов, 2017). Но речь не об этом.

Мы уже писали подробно о концепциях диджимодерна, автомодерна и метамодерна (Павлов, 2018abc). Цель этой статьи - анализ понятия «сверхмодернизм», который был введен в научный оборот французским антропологом Марком Оже в работе «Не-места. Введение в антропологию гипермодерна» (Augé, 1992), а впоследствии использовался другими авторами - историком архитектуры Гансом Ибелингсом и историком Альфредо Гонзалесом-Руибалом (Ibelings, 1998; Gonzalez-Ruibal, 2008). В дальнейшем изложении я собираюсь осветить несколько пунктов. Объясню, почему русский перевод термина «surmodernité» как «гипермодерн» (Оже, 2017) не вполне корректный. При этом отмечу, что как таковой русский перевод книги Оже - качественный. Поэтому, излагая суть концепции Оже, обращаться я буду именно к переводному изданию. Так, я эксплицирую основные интуиции автора относительно нового модерна. Аалее рассмотрю вопрос о том, имеет ли (и если нет, то имело ли) его «введение» в антропологию сверхмодерна эвристическую ценность. И, наконец, расскажу, получила ли его идея «сверхмодерна» дальнейшее развитие, и если да, то насколько это оказалось успешно. Обсудив все эти вопросы, мы увидим, может ли быть концепция Оже качественной и работоспособной альтернативой постмодерну сегодня, как утверждает цитируемая выше Хатчеон, ушедшему в прошлое. 
ПРЕАВАРИТЕАЬНЫЕ ЗАМЕЧАНИЯ

Стоит признать, что сами исследователи постмодерна критически относились к предмету своего интереса и, чувствуя «дух времени», уже в первой половине 1990-х, т. е. за 10 лет до Хатчеон, признавались, что постмодерн, кажется, перестает быть актуальным.

Так, социолог С. Аэш в предисловии к своей книге 1990 г. заметил: «Постмодернизм, очевидно, уже не в моде» (Lash, 1990: ix). Немногим позже культурсоциолог Аж. Александер точно так же выразил сомнения насчет жизнеспособности как термина, так и самого феномена, что бы под ним ни понималось: «Если, как я полагаю, отход от постмодернизма уже начался, то нам снова необходимо тщательно рассмотреть вненаучные факторы, недавние события и социальные изменения, которые, по-видимому, требуют еще одной новой “всемирно-исторической схемы” (Александер, 2013: 562-563).

Но если цитируемые социологи лишь чувствовали некоторую усталость от понятия и только-только разглядывали закат постмодерна, были авторы, которые попытались уже в это время сказать новое слово в социальной и культурной теории. ОАним из таких исследователей оказался французский антрополог М. Оже.

В 1992 г. Оже наметил основы своей концепции «новой современности» и предложил термин «сверхмодерн» в качестве ярлыка новой глобальной эры (Augé, 1992). Однако прежде чем мы проясним суть этой концепции, необходимо сделать несколько важных замечаний. Во-первых, книга, в которой Оже описал суть своего подхода, переведена на русский язык, что само по себе прекрасно, хотя это и было сделано лишь в 2017 г. В переводе его книга называется «Не-места. Введение в антропологию гипермодерна» (Оже, 2017). Несмотря на то что в целом перевод текста сделан качественно, ключевой для Оже термин («сверхмодерн») был переведен некорректно. В оригинале на французском языке это «surmodernité», где приставка «sur...» обозначает не «гипер...», как предположил переводчик, но «сверх...», а буквально - «над...». Семантическая разница этих приставок очевидна: если «гипер...» усиливает модерн, то «сверх...» его превосходит и возвышается над ним. Аля иллюстрации этой мысли можно было бы привести аналогию с другой парой терминов, связанных с эстетикой: «гиперреализм» и «сюрреализм», где первый усиливает реальность, доводя ее до предела, в то время как второй возвышается и делает реальность сверхреальной. Если ознакомиться с идеями Оже ближе, сразу станет понятно, в чем различие между «гипермодерном» и «сверхмодерном».

Кроме того, и это во-вторых, существуют разные версии «гипермодерна», наиболее влиятельной из которых является концепция французского социального филоcoфа Жиля Аиповецкого (Lipovetsky, 2015). В таком свете получается, что два французских исследователя предложили одинаковые языки описания нашего времени, используя одно название, но разное содержание. А это, конечно, совсем не так.

В-третьих, русский перевод книги Оже вышел в серии издательства «Новое литературное обозрение» «Studia Urbanica», указывая на то, что идея «сверхмодерна» в русскоязычном академическом пространстве вписывается в контекст «урбанистики» и, по большому счету, обманывает читателя - про сам город и городское пространство Оже говорит очень мало, предлагая лишь введение в новую на тот момент антропологию.

Наконец, в-четвертых, в отечественном публичном пространстве уже существует термин «сверхмодерн»: его активно используют авторы, например С. Ф. Черняховский (Черняховский, 2013). Аля него «сверхмодерн» является исключительно политической категорией (мыслитель концентрируется на поисках «новой сакральности» / 
с опорой на традиционные российские ценности), и тем самым одно и то же понятие у Оже и у российских политологов наполнено совершенно разным содержанием. Аруг от друга эти концепции настолько же далеки, насколько далеко находятся друг от друга «сверхмодерн» и настоящий «гипермодерн» (Lipovetsky, 2015; Kroker A., Kroker M., 1988).

Стоит заметить, что к идеям Оже обращается и даже пытается их развивать философ В. И. Спиридонова. Однако она использует перевод слова «surmodernité», предложенный издательством Н $\Lambda \mathrm{O}$, и тем самым, разрабатывая концепцию Кургиняна и Черняховского, скорее вписывает «гипермодерн» (а на деле - сверхмодерн) в их политологические теории. Ирония в том, что сама Спиридонова говорит буквально следующее: «Вслед за разочарованием в постмодерне в российской интеллектуальной мысли, так же, как и на Западе, стала оформляться идея “сверхсовременности”. ОАнако то явление, которое на Западе обозначается как “гипермодерн”, радикально расходится по смыслу с той категорией, которая предлагается российскими исследователями и называется “сверхмодерном”» (Спиридонова, 2017: 41).

То есть расходятся на Западе и в России именно две версии сверхмодерна. Если делать из этого - четвертого - замечания какой-то вывод, то можно сказать, что российские авторы строят свои концепции не вполне с соответствием исследовательского этоса: они производят новые теории, не обращая внимания на то, что было сказано до них. Благодаря этому исследователи, например Спиридонова, все же, обращаясь к уже сказанному учеными на Западе, делают не вполне корректные заключения, лишь внося путаницу и в без того не освоенную у нас тему.

Я бы хотел сосредоточиться на концепции Оже, имеющей некоторое звучание и в XXI столетии.

\section{ЧTO TAKOE CBEPXMOАEPH}

Начать следует с того, что Оже исходит в своих рассуждениях прежде всего из антропологической перспективы, при этом понимая под антропологией именно то, что ею считалось первоначально - исследование досовременных (традиционных) экзотических форм общественной жизни, т. е. типов коллективного участия аборигенов. В первой же главе «Ближнее и далекое» автор пускается в размышления о том, что отличает антропологию от этнологии. С точки зрения автора, если последняя занимается главным образом описанием, т. е. обязательно показывает результаты полевой работы, то первая предполагает уровень вторичных обобщений, представляя некоторые аналитические выводы, не ограниченные исключительно описательной работой. Иными словами, антропология использует уже имеющийся материал, но этот материал должен быть кем-то собран. По мнению исследователя, ситуация начала 1990-х годов свидетельствует в пользу того, что ныне антропология, сохраняя свои исходные методологические принципы, должна обратиться к новым предметным областям и начать изучать не досовременные ( «далекое»), а современные общества («ближнее»), т. е. актуальный на тот момент западный мир и всевозможные трансформации социальной жизни этого мира.

Сам автор считает, что ситуация сверхмодерна характеризуется тремя избытками: избытком времени, избытком пространства и индивидуализацией референций. Мы начнем с конца. Последний пункт Оже проговаривает лишь вскользь. Именно в этом вопросе антрополог обращается к критике постмодерна, настаивая, что антропологи должны изучать в качестве эмпирического материала не тексты, предлагая его всевоз- 
можные интерпретации, но конкретно индивида. И вместо герменевтики, в которой ученые подменяют «полевые исследования исследованием личностей полевых исследований» (Оже, 2017: 43), нужно работать над тем, чтобы производить индивидуальный смысл. Аалее. Избыток пространства коррелирует с «уменьшением» планеты, и внутрь домов западного человека посредством телевидения проникают различные изображения. И хотя, как считает автор, мы в состоянии определить искажение информации, в целом «на экранах по всему земному шару ежедневно смешиваются образы из новостей, рекламы и художественных произведений. ...Они при әтом составляют - прямо у нас перед глазами - относительно однородный в своем многообразии мир» (Оже, 2017: 38). Наконец, избыток времени. Согласно исследователю, в жизни каждого конкретного человека сегодня происходит так много событий, что они, вытесняя друг друга и тем не менее образуя личную историю, вплетаются в «Историю всеобщую».

При всем этом, что очень важно, речь идет не о западном мире, хотя Оже, очевидно, обсуждает исключительно развитые страны, но о современности как таковой. Поэтому он формулирует ту новую дисциплину, которую и пытается развивать, - «антропология ближнего» или «антропология современности». Как об этом говорит сам антрополог, «вопрос об условиях, при которых осуществима антропология современности, должен быть обращен не на метод, а на предмет» (там же: 46). И потому антропология Оже все еще остается антропологией - основным объектом его интереса по-прежнему является индивид (человек), а не общество и уж тем более не культура, поскольку, во-первых, как считает он, социальное начинается с индивида, а во-вторых, именно средний человек, в формулировке автора, остается некой тотальностью, которая может и должна быть изучена.

Во второй главе «Антропологическое место» Оже много рассказывает о том, чем антропология была раньше и как классические антропологи, такие как М. Мосс, говорили о традиционном обществе. При әтом автор делает особый акцент на том, что называется «антропологическим местом». Под последним исследователь понимает смыслоорганизующую территорию для тех, кто ее населяет (и для тех, кто его изучает). Такие пространства имеют совершенно разный масштаб - дом, площадь, рынок и т. А. У данных территорий три принципа - люди стремятся сделать такие «пространства» точками формирования идентичностей, отношений и истории (Оже, 2017: 58). Однако все это относится к местам «далекого».

Сегодня же «ближние» места, считает автор, могут выступать и структурами власти, т. е. символом властных отношений, и памятными местами, и даже субъектами (в оригинале - des hommes, см.: Augé, 1992: 82). Примерами таких мест могут служить «Белый дом» или «Кремль». Чтобы проиллюстрировать свою идею, Оже обращается к опыту Франции, описывая, как ее города стремятся к приданию практического смысла своего существования: каждая административная единица хочет быть также специфическим экономическим субъектом - «гастрономической столицей» Франции

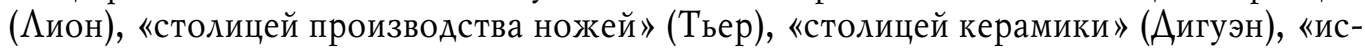
конным производителем фермерской курятины» (Жанзэ), и все в таком духе. К слову, можно вспомнить, что Санкт-Петербург считается «культурной столицей России», т. е. главным производителем (и, конечно, не только производителем) культурных благ, и, таким образом, сказанное Оже относится и к отечественным реалиям. Очень часто эта стратегия смыслообразования строится на том, чтобы доказать свой статус «исторического памятника»: «Ссылка на прошлое делает настоящее более сложным» 
(Оже, 2017: 75). Например, сразу несколько городов или деревень могут считать себя малой родиной того или иного исторического персонажа. По тому же принципу власти стараются действовать относительно дорог, перекрестков и т. А., давая им «исторические названия» или расставляя указатели, свидетельствующие о том, что водитель проезжает мимо «исторического места». Все это приводит к тому, что образуются новые антропологические единицы, именуемые Оже «не-местами». Так, согласно Оже, водители, которые едут по своим делам, проезжая мимо обозначенных «памятников культуры», скорее всего никогда не останавливаются, чтобы посмотреть их и лишь фиксируют, что проезжают мимо какого-то знакового пространства.

Последняя тема обсуждается уже в третьей главе «От мест - к не-местам». Под последними Оже понимает пункты временного пребывания и промежуточного времяпрепровождения - гостиницы, аэропорты, супермаркеты, лагеря беженцев и т. А. все то, где, с точки зрения автора, отсутствует идентичность субъекта. Оже обращается к идее М. де Серто о разграничении места и пространства, но дишь затем, чтобы в итоге от нее отказаться, показав, что сам он думает иначе. Так, для де Серто пространство важнее места, потому что последнее становится первым, если используется на практике (Серто, 2013: 219). Иными словами, пешеходы превращают место в пространство за счет движения тел. Тем самым разница между местом в понимании Оже и местом в понимании де Серто становится очевидной. Аля де Сорто место - нечто, что еще предстоит анимировать, т. е. наделить смыслом за счет движения; для Оже место - что-то обладающее установленным символическим значением. Отсюда разница и в понимании пространства. Аля Оже пространство - это не-места, т. е. «места, которые не являются антропологическими местами», которые нельзя определить ни через историю, ни через идентичность, ни через связи (Оже, 2017: 84). Поэтому неместа предполагают отсутствие истории и даже ее упразднение. И поскольку в таком пространстве нет ничего, мы приходим к новому измерению этой области - экзистенциальному, а через него и на более широкой уровень - социальный и политический, о чем будет сказано далее.

Экзистенциальное измерение концепции Оже заключается в следующем: именно в не-местах человек проживает свое одиночество, «выходит за пределы себя» и утрачивает (истощает) собственную индивидуальность. И поскольку в соответствии с появлением сверхмодерна возникают две новые реальности - с одной стороны, это пространства, созданные с конкретными целями типа торговли и путешествия, с другой - реальность, в которой современные субъекты должны вступать в отношения с этими пространствами, где происходит, как говорит сам Оже, переконфигурация субъекта, очень важно, что субъекты в не-местах не коммуницируют друг с другом теперь они просто вынуждены внимать «тексту». Например, «застегните ремни», «наберите пин», «держитесь левой стороны» и проч. Именно такой «текст» говорит о том, что вы пребываете в не-месте, где вам дают инструкции, содержащие указания («встаньте в правый ряд»), запреты («курить запрещено») и оповещения («вы въезжаете в...»). Вот почему если антропологические места создают «социальное», то не-места образуют «уединение по договоренности» (там же: 102-103). Более того, социальный аспект сверхмодерна заключается в новой анонимности, возможной только после подтверждения личности. Вы становитесь «средним человеком» (пользователем банкомата, покупателем, пассажиром воздушного судна) лишь после того, как поставили подпись под договором - купили билет, показали паспорт, набрали пин-код и проч.: «пользователь не-места всегда должен доказывать свою невиновность» (там 
же: 111). Автор не раскрывает термина, но, кажется, имеет в виду то, что не-места действуют по принципу презумпции виновности - ты виновен (а значит, не можешь стать пользователем не-места) до тех пор, пока не доказал обратного, показав паспорт или введя пин. Иначе говоря, «критерии невиновности - это установленные, официальные критерии индивидуальной идентичности» (там же). И как «средний человек» (и невиновный) в не-месте освобождаетесь от своих обычных детерминант. Поэтому в ситуации сверхмодерна, считает Оже, мы должны говорить о новой антропологии «антропологии одиночества».

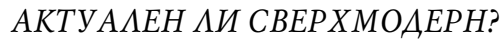

Итак, спустя более чем 25 лет с момента появления идеи сверхмодерна можем ли мы сказать, что она все еще актуальна? Была ли она в принципе актуальна? Начать следует с того, что Оже лишь пунктирно наметил контуры своей концепции, не затронув многих аспектов современности. Аогика развития его мысли на протяжении книги понятна и даже оправдана, однако вместе с тем в ней есть уязвимые для критики места.

Так, первая и самая очевидная проблема Оже состоит в том, что он не дает себе труда объяснить, что именно подразумевает под постмодерном. Это слово возникает у него три-четыре раза на протяжении книги, и то всегда как антитеза сверхмодерна. Мы можем лишь косвенно судить о том, чем ему представляется постмодерн. Во-первых, хотя он и не упоминает конкретных имен, это деконструкция, популярная в качестве метода у антропологов в начале 1990-х годов. Во-первых, он пишет о «редукционистском методе» постмодернистской антропологии следующим образом: «от поля к тексту, от текста к автору» (Оже, 2017: 43). Во-вторых, уже в другом месте Оже, видимо, приписывает постмодерну лиотаровскую идею об исчезновении метанарративов: «Гипермодерн, можно сказать, является лицевой стороной того, изнанкой чего нам извечно представляется постмодерн, - утверждением отрицания. С точки зрения гипермодерна сложность осмысления времени объясняется избытком событий, происходящих в современном мире, а не крушением идеи прогресса, уже давно шаткой по крайней мере, в своих карикатурных формах» (там же: 36). Наконец, в-третьих, Оже настаивает на том, что «возникающее лоскутное одеяло способов интерпретации означает стирание современности» (там же: 32). Что ж, следует сказать, что это очень и очень поверхностные представления о постмодерне. И вот почему.

Ясно, что Оже немного знаком с тезисами Ж.-Ф. Аиотара и Ж. Аеррида и при этом обходит стороной идеи Ж. Бодрийяра (кстати, использование приставки «сверх...», а не «гипер...» может косвенно подтверждать то, что Оже не хотел связываться с терминологией, уже «забронированной» Бодрийяром). Однако все это - не постмодерн. С тех пор как американский марксист $Ф$. Ажеймисон выступил со своей программной статьей «Постмодернизм, или Культурная логика позднего капитализма», ставшей заглавием его книги (Ажеймисон, 2019), обычно, хотя и не всегда, под постмодерном стали понимать уже не метод, но язык описания эпохи, т. е. темпоральную категорию. В своей критике я буду исходить из того, что считаю, что Ажеймисон предложил наиболее адекватное представление о постмодерне, а этот тезис, кстати, был подтвержден временем, а не только еще одним марксистом П. Андерсоном, возвеличившим идеи Ажеймисона (Андерсон, 2011). Если изучить ключевой текст Ажеймисона, то станет ясно, что постмодерн как эпоха характеризуется именно утратой исторического мышления. В таком свете не-места Оже предстают всего лишь иллюстрацией ут- 
верждения состояния постмодерна. Там, где нет истории или же где история предстает в виде текста (например, табличек памятных мест), там постмодерн являет себя в его полноценном виде: «Мы обречены искать Историю при помощи поп-образов и симулякров этой истории, которая останется для нас навеки недостижимой» (Ажеймисон, 2019: 125). И даже более того: то, на чем делает акцент Оже, на поверку оказывается еще одной характеристикой постмодерна: «...сама характеристика времени... привлекает внимание к переменам в повседневности и переменам на собственно культурном уровне» (курсив наш. - $A$. П.) (там же: 80).

Если делать какой-то промежуточный вывод, то можно сказать, что Оже на тот момент лишь подтверждает актуальность постмодерна, нежели упраздняет его.

Но есть и более простые способы найти слабые стороны в концепции Оже, и они касаются прежде всего социально-политических экспликаций. Условно назовем это «второй проблемой». Во-первых, теория Оже уязвима для марксистской критики. Признаем, что все же банкоматы, карты в супермаркете и путешествия на самолетах и автомобилях в начале 1990-х были прерогативой в лучшем случае состоятельных людей западных обществ. Ааже сегодня, в XXI в., далеко не у всех есть автомобили, а многие часто не имеют возможности путешествовать и в лучшем случае, находясь на заработках в другой стране, лишь находят средства на поездку домой раз в год. А сколько из жителей стран Африки могут позволить себе путешествовать? И вот почему, несмотря на все декларации Оже о том, что он ведет речь не о Европе, тем не менее говорит он вовсе не о «ближней современности», но о «ближнем Западе». Ведь сверхсовременным является именно этот регион, а весь остальной мир, что нам и так хорошо известно, остается «недосовременным».

Во-вторых, сверхмодерн не оправдал себя в следующем социальном отношении. Оже утверждает, что не-места приглашают индивидов к самоидентификациям, которые «по существу являются мужскими, поскольку идеал “я", распространяемый ими, по сути своей мужской» (Оже, 2017: 114). Сегодня феминизм, часто отождествляемый с постмодернизмом, одержал внушительную победу - особенно, кстати, на Западе - не только в социальной сфере, но и в вопросе языковых норм и репрезентаций, и многим феминисткам было бы неприятно и (или) смешно читать цитируемые слова автора.

В-третьих, Оже так увлекается своими рассуждениями, что порою доходит до совсем уже спорных тезисов.

Самый спорный момент в концепции Оже следующий. Он считает, что аэропорты, вокзалы и супермаркеты всегда были основными местами для совершения террористических атак по причине их «эффективности», «но, возможно, здесь кроется другая причина: те, кто стремится к новым формам социализации и локализации, видят в этих местах более и или менее отчетливое отрицание своих идеалов. Не-место является противоположностью утопии: оно существует, не содержа в себе ничего органически социального» (курсив наш. - A. П.) (Оже, 2017: 121) Вряд ли мы можем подтвердить эти слова, имея в памяти хотя бы теракт 11 сентября 2001 г. Но это касается большинства всех террористических атак. Более того, как видно из цитаты, Оже называет не-места местами. Но дело не столько в этом. Смущает то, что вокзалы, аэропорты, станции метро и торговые центры больше олицетворяют для террористов «отрицание идеалов», нежели просто «удобны». Торговые центры на самом деле сегодня являются лучшим примером новых форм социальности, так как становятся одной из главных досуговых площадок для потребителей в регионах, где не так много пространства для развлечений. 
Аалее. Сам Оже заводит разговор об империи, утверждая, что последняя, разумеется, не являясь не-местом, представляет собой пережиток прошлого, отражая «парамодерность» и неудачи модерна, а потому не отображает аспекты сверхмодерна и обречена на провал (Оже, 2017: 123-124). Не беря в расчет то, что имперский дискурс сегодня до сих пор в силе, мы можем вспомнить влиятельную концепцию М. Хардта и А. Негри, переосмысливших империю как новый мировой порядок без границ и пределов. Более того, авторы считают, что периоду империи соответствует «постмодернизация» экономики, т. е. переход от производства к сфере услуг и информатизации (Хардт, Негри, 2004: 263-283).

Наконец, третья существенная проблема концепции сверхмодерна Оже связана с очевидным - социальностью не-мест, на что автор отказывается обращать внимание. Например, люди редко путешествуют одни, потому отнюдь не обрекают себя на одиночество, проводя время в залах ожидания с семьей или друзьями, равно как разъезжая на автомобиле в веселой компании. Сверх того, некоторые не-места с исторической точки зрения представляют собой именно места - исторически и культурно важные построения типа Центрального вокзала или аэропорта имени Ажона Кеннеди в Нью-Йорке. Иными словами, часто не-места оказываются местами по причине того, что предполагают и социальные отношения, и даже некоторую историю. Наконец, все это связано с непредвиденными Оже трансформациями общества и культуры, в частности диджитализацией 1 . Благодаря Интернету, ноутбуку и смартфону человек ныне остается социальным, даже будучи изолированным в не-местах: без каких-либо ограничений мы продолжаем работать в залах ожидания, общаемся с семьей, друзьями, коллегами. Одним словом, цифровые технологии отменили «антропологию одиночества», которую пророчил обществу Оже, а вместе с этим исчез и сверхмодерн, оказавшись любопытной, но несостоявшейся социально-философской концепцией.

\section{ЖИЗНЬ И ВРЕМЕНА СВЕРХМОАЕРНА}

Вместе с тем, в отличие от многих других концепций постпостмодернизма (например, альтермодернизма), сверхмодернизм в некотором роде оказался востребованной идеей. Нашлись такие авторы, которые посчитали теорию достаточно эвристичной, чтобы попытаться развить ее, применив к иным сферам. го ее попытались развить в двух областях, далеких от классической антропологии, в истории архитектуры и в «новой археологии».

Первым, кто решил связать свои интеллектуальные поиски со сверхмодерном, оказался нидерландский критик и историк архитектуры Г. Ибелингс. Он непосредственно обращается к Оже, чтобы описать актуальную на момент конца 1990-х годов архитектуру как «сверхсовременную» в книге «Сверхмодернизм. Архитектура в эру глобализации» (Ibelings, 1998). Однако идея не-мест, кажется, не слишком привлекла указанного автора, поскольку для него сосредоточенность индивидуальной жизни в аэропортах и проч. - всего-навсего факт глобализации (термин, отсутствующий в размышлениях Оже), потому что в эпоху информации и технологий преобладает идеал безграничного и неопределенного пространства - своего рода сверхсовременности. Стоит признать, что рассуждения Ибелингса весьма любопытны (например, он берет в расчет компьютерные технологии, делает особый акцент на значении городов и их дизайна, а также вводит в оборот понятие «архитекторов-звезд» 2 , вместе с тем речь идет именно об архитектуре, а не о социальности и уж тем более систематическом описании нашего времени). 
Ирония заключается в том, что Ибелингс, заимствуя термин, противоречит тому, что хотел сказать сам Оже. Если для Оже сверхмодерн производит не-места - пространства, в которых нет истории, то для Ибелингса сверхмодерн - это городская архитектура, т. е. не аэропорты и супермаркеты, но буквально «антропологические места» с вытекающими из этого последствиями социальной и исторической жизни.

В свою очередь, уже идеи самого Ибелингса об архитектуре оказались востребованы некоторым образом. Так, канадский философ М. Кингвелл заимствовал термин, предложенный Оже и переосмысленный Ибелингсом, для того, чтобы попытаться «скрестить» рассуждения о современной архитектуре со своими познаниями в социальной и политической философии (Kingwell, 2006). Кингвелл добавил в свои рассуждения Аж. Ролза, Аж. Грея, Ю. Хабермаса и проч. с целью разыграть карту сверхмодерна, т. е. термина, на который можно было сделать ставку как на ключевой ярлык, альтернативный постмодерну. Текст Кингвелла не дал никакого интеллектуального прироста для развития теории сверхмодерна (за исключением использования слова «меганарратив» вместо «метанарратив») и, по сути, представляет собой «холостую академическую статью», призванную показать эрудицию автора и способность сплетать сложные предложения на конкретную тему. В свою очередь, английский историк и теоретик архитектуры Р. Адам в книге «Глобализация архитектуры модерна» хотя и упоминает Ибелингса, уже не связывается с термином, благоразумно предпочитая более конвенциональные и понятные всем слова «модерн» и «модернизм» (Adam, 2012: 125).

Позже на концепцию Оже обратили внимание в Испании. В 2008 г. историк А. Гонзалес-Руибал позаимствовал термин непосредственно у Оже в статье «Время разрушать. Археология сверхсовременности» (Gonzalez-Ruibal, 2008). Однако, кажется, близость двух концепций сверхмодерна этим и ограничивается. После краткого экскурса в теорию Оже Гонзалес-Руибал объясняет, почему он решил использовать именно это понятие. Во-первых, потому что приставка «сверх...» подразумевает обострение и преувеличение, в то время как приставка «пост...»- преодоление. С точки зрения исследователя, современность не преодолена, а ее материальная природа требует объяснения кризиса индустриализма, колониализма и экологического кризиса. Во-вторых, как правило, археологи, как утверждает сам автор, изучают период с начала XVI в. и заканчивают свои поиски началом XX, в то же время материальная культура XX и начала XXI столетий выпадает из поля зрения историков. B-третьих, археология сверхмодерна - актуальная для нас история, буквально «наша история», и еще больше это «история травмы», которую необходимо изучать. Наконец, в-четвертых, если современность в целом приносит разрушение, то сверхсовременность производит ее в необычайных масштабах. Самым ярким примером, который приводит Гонзалес-Руибал, являются войны, однако сверхсовременная повседневная жизнь, с его точки зрения, приносит миру больше вреда, чем две мировые войны (GonzalezRuibal, 2008: 247, 248). Сверхсовременность, как и современность в целом, настолько же характеризуется разрушением, насколько производством или потреблением, с той лишь разницей, что разрушение обычно игнорируется исследователями.

Фактически моя статья должна была бы называться не «Образы современности в XXI веке: сверхмодерн», но «в XX веке» - поскольку исходная теория Оже принадлежит прошлому, а в XXI столетии, казалось бы, для нее нет места. Однако концепция Гонзалеса-Руибала оправдывает выбранное название. Как настаивает он сам, его идея не должна быть принята за попытку отделить прошлое от настоящего: «Здесь нет археологии двадцать первого века, но есть лишь археология двадцать первого сто- 
летия и всех прошлых столетий, смешанных и запутанных» (там же: 262). Как признается автор, его концепция пессимистична. Однако это не парализующий пессимизм, но тот, который призывает к действию. Последнее может быть представлено как «археологическая терапия» и «археологическая критика», т. е. способ справиться с травмирующим прошлым и управлять противоречивыми воспоминаниями. Миссия археологии сверхсовременности состоит не только в том, чтобы рассказывать (откапывать) истории разрушения, но и в том, чтобы воскресить память о репрессированных людях. Именно с этой точки зрения археология может выполнять как терапевтическую, так и политическую функцию. Гонзалес-Руибал заявляет, что написать манифест означает совершить политический акт - разоблачить то, что сверхсовременная силовая машина не хочет показывать, например трупы в боснийской братской могиле.

В отличие от разысканий Ибелингса и других историков архитектуры, концепция Гонзалеса-Руибала выглядит куда более убедительной, продуманной и полезной с точки зрения социальной философии. Вместе с тем термин, им используемый, очевидно, не имеет отношения к не-местам Оже. Наряду с этим, сколь бы привлекательной ни выглядели исследования автора, по сути, они имеют дело с тем, что культурсоциолог Ажеффри Александер назвал «темной стороной современности» (Alexander, 2013). На деле «археология сверхсовременности» занимается «культурной травмой» и относится к сфере культурных исследований и истории. В журнале «Антропология сегодня», в котором опубликована статья Гонзалеса-Руибала, представлено много ответов (комментариев): концепция вызвала неподдельный интерес. Тем не менее уже в сборнике әссе, который редактировал Гонзалес-Руибал, про сверхмодерн практически не вспоминают - на всю книгу приходится два-три упоминания (Reclaiming Archaeology ... , 2013). Гонзалес-Руибал также написал статью «Сверхсовременность и археология» Аля энциклопедии глобальной археологии (Gonzalez-Ruibal, 2014), в которой скорее размыл понятие, сосредоточившись не на своих предшествующих исследованиях, но вписав концепт в хорошо известную дискуссию о постмодерне современных социальных теоретиков, с акцентом на теории Оже. Таким образом, идея «сверхмодерна», обреченная на поражение, получила новую, но весьма ограниченную жизнь.

\section{ЗАКАЮЧЕНИЕ}

В антологию постпостмодернизма, упоминаемую в самом начале статьи (Supplanting the Postmodern ..., 2015), концепция Оже и ее не самых надежных сторонников типа Ибелингса и Гонзалеса-Руибала не попала. Главным образом потому, что эти идеи антропологии были сформулированы задолго до появления самого постпостмодернизма. И хотя ее недостатки и несостоятельность в качестве альтернативы постмодерну очевидны, в целом нам необходимо признать ее значение в качестве одной из первых попыток поиска нового языка описания эпохи XXI в. Несмотря на это, сверхмодерн, отражая общее настроение ухода постмодерна с исторической сцены, разумеется, должен быть вписан (и, по сути, вписывается, что и было показано) в общее движение постпостмодернизма.

Здесь, в заключении, хотелось бы обратить внимание на следующее. Как уже говорилось, М. Оже, в действительности обращаясь к «культуре повседневности» - вполне в постмодернистском духе, - отдает приоритет антропологии и умаляет значение культуры во всех ее формах типа музыки, живописи, книг (хотя и часто цитирует Бодлера и обращается за помощью к Шатобриану). Вместе с тем иные варианты постпостмодернизма очень часто прибегают как к культуре в целом, так и к ее конкретным 
формам, в особенности - к кинематографу. Так, самым важным фильмом для теории автомодернизма оказывается «Парк Юрского периода» (1993), для диджимодернизма - «Аватар» (2009), для метамодернизма - творчество Уэса Андерсона, для перформатизма - «Красота по-американски» (1999) и т. А.

Существует, однако, несколько фильмов, которые могли бы стать ключевыми для прояснения социального статуса не-мест. Это «Подземка» (1985) где сердце» (2000) Мэтта Уильямса и «Терминал» (2004) Стивена Спилберга. Во всех этих картинах не-места фактически становятся иным пространством - пространством не временного пребывания, но жизни вообще. В «Терминале» главный герой вынужден буквально жить в аэропорту имени Ажона Кеннеди, не имея возможности ни уехать на родину, ни выйти в город. Равно как и героиня «Там, где сердце» устраивает свой быт в придорожном супермаркете, потому что ей больше некуда идти. Случай сюрреалистического мира «Подземки» более сложный, поскольку в этой ленте само метро оказывается «антропологическим местом», смысл которого образуют его жители, не поднимающиеся наверх. Однако эти не-места, представляемые художниками как «места» (в терминологии Оже), уникальны и, по сути, за счет того, что являются эксцессами, нетипичными примерами для типичных феноменов, подтверждают концепцию сверхмодерна.

Однако фильм Кевина Смита «Тусовщики в супермаркете» (1995), вышедший почти сразу после публикации книги Оже (и в момент ее перевода на английский язык), полностью опровергает теорию сверхмодерна: оказывается, вся культурная жизнь человека, буквально повседневная жизнь, может протекать в не-местах. Что еще более важно - речь идет о социальной жизни, а не об одиночестве индивида. И эта реалистическая (а не сверх- или сюрреалистическая) картина выражает уже не эксцесс, но напротив, рутину и обыденность.

В целом мы видим, что, во-первых, сам Оже не стал развивать свое «введение в антропологию сверхмодерна», а многие его интуиции себя в итоге не оправдали. Во-вторых, другие авторы, обращаясь к термину по случаю, также в дальнейшем не стали развивать свои идеи. Таким образом, можно сделать вывод, что сверхмодернизм не является работоспособной концепцией и не может считаться даже слабой альтернативой постмодернизму.

\section{ПРИМЕЧАНИЯ}

1 От слова Digital - цифровой. Кстати, британский теоретик культуры Алан Кирби разработал концепцию диджимодернизма, цифрового модерна, якобы упразднившего постмодерн (Павлов, 2018а).

${ }^{2} \mathrm{C}$ точки зрения Ибелингса, в ситуации конца XX в. настоящими звездами стали архитекторы - наиболее востребованные на мировом рынке проектировщики зданий и даже кварталов или городов, суммы гонораров которых сравнимы с гонорарами ведущих голливудских актеров. Поскольку таких архитекторов не так много, их услуги пользуются невероятным спросом.

\section{СПИСОК АИТЕРАТУРЫ}

Александер, Аж. (2013) Смыслы социальной жизни: культурсоциология. М. : Праксис. 640 с.

Андерсон, П. (2011) Истоки постмодерна. М. : Территория будущего. 208 с.

Серто, М. де (2013) Изобретение повседневности. СПб. : Изд-во Европейского университета в Санкт-Петербурге. 330 с.

Ажеймисон, Ф. (2019) Постмодернизм, или Культурная логика позднего капитализма. М. : ИзА-во Института Гайдара. 808 с. 
Кузнецов, В. (2017) Постсекулярный век неомодерна. Ближневосточный извод // Государство, религия, церковь в России и за рубежом. № 3. С. 85-111.

Оже, М. (2017) Не-места. Введение в антропологию гипермодерна. М. : Новое литературное обозрение. 136 с.

Павлов, А. В. (2018а) Образы современности в XXI веке: диджимодернизм: рецензия на книгу Алана Кирби // Философия. Журнал Высшей школы экономики. Т. 2. № 2. С. 197-212.

Павлов, А. В. (2018b) Образы современности в XXI веке: автомодернизм // Философские науки. № 10. С. 97-113.

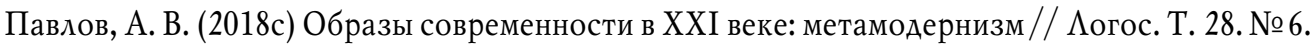
C. $1-19$.

Спиридонова, В. И. (2017) «Новая современность» и традиционные ценности // Философские науки. № 6. С. 35-49.

Хардт, М., Негри, А. (2004) Империя. М. : Праксис. 440 с.

Черняховский, С. Ф. (2013) Традиция, модерн и сверхмодерн // Перелом. Сборник статей о справедливости традиции / сост. А. Щипков. М. : ПРОБЕ $\Lambda-2000.176$ с. С. 16-25.

Adam, R. (2012) The Globalisation of Modern Architecture: The Impact of Politics, Economics and Social Change on Architecture and Urban Design Since 1990. Cambridge : Cambridge Scholars Publishing. 360 p.

Alexander, J. C. (2013) The Dark Side of Modernity. Cambridge : Polity. 187 p.

Augé, M. (1992) Non-lieux, introduction à une anthropologie de la surmodernité, Seuil : La Librairie du XXe siécle. 160 p.

Gonzalez-Ruibal, A. (2008) Time to Destroy. An Archaeology of Supermodernity // Current Anthropology. Vol. 49. № 2. P. 247-279.

Gonzalez-Ruibal, A. (2014) Supermodernity and Archaeology // Encyclopaedia of Global Archaeology / ed. by Smith C. New York : Springer. 8015 p. P. $7125-7134$.

Hutcheon, L. (2002) The Politics of Postmodernism. New York ; London : Routledge. 222 p.

Ibelings, H. (1998) Supermodernism. Architecture in the Age of Globalization. Rotterdam : NAi Publishers. 160 p.

Kingwell, M. (2006) Meganarratives Of Supermodernism: The Spectre Of The Public Sphere // PhaenEx. № 1 (spring/summer). P. 197-229.

Kroker, A., Kroker, M. (1988) Theses on the Disappearing Body in the Hyper-Modern Condition // Body Invaders. Sexuality and the Postmodern Condition / ed. by Kroker A., Kroker M. Houndmills, Basingstoke, Hampshire, London : Macmillan Education UK. 256 p. P. 20-34.

Lash, S. (1990) Sociology of Postmodernism. London; New York : Routledge. 300 p.

Lipovetsky, G. (2015) Time Against Time, or The Hypermodern Society // Supplanting the Postmodern. An Anthology of Writings on the Arts and Culture of the Early 21st Century / ed. by Rudrum D., Stavris N. New York, London, New Delhi, Sydney : Bloomsbury Academic. 402 p. P. 191-208.

Reclaiming Archaeology. Beyond the Tropes of Modernity (2013) / ed. by A. Gonzalez-Ruibal. London; New York : Routledge. 375 p.

Supplanting the Postmodern. An Anthology of Writings on the Arts and Culture of the Early $21^{\text {st }}$ Century (2015) / ed. by Rudrum D., Stavris N. New York ; London ; New Delhi ; Sydney : Bloomsbury Academic. 400 p.

Аата поступления: 12.01.2019 2.

\section{IMAGES OF MODERNITY IN THE 21ST CENTURY: SUPERMODERNISM}

\section{A. V. PAVLOV}

RAS INSTITUTE OF PHILOSOPHY

Since the 1990s, many social theorists, culturologists and philosophers have been talking about the extinction or even death of postmodernism not so much as a philosophical trend but rather as a historical period. By 2000, a consensus had emerged on this point, which was voiced by the literary schol- 
ar and leader in postmodern research Linda Hutcheon, who announced an open competition for various concepts of post-postmodernism. This article is devoted to one of the earliest alternatives to postmodernism - supermodernism - the emergence (the theory of the French anthropologist Mark Augé) and the development of the concept and the term itself by other authors (such as the Dutch historian of architecture Hans Ibelings and the Spanish "archaeologist of modernity" Alfredo GonzalezRuibal).

The author explains why the Russian translation of the term "supermodern" as "hypermodern" is highly incorrect, presents the essence of Augé's theory (in particular, his idea of "three excesses" of supermodern - time, space and individual references), and compares the approach of Augé and the thinkers who adopted the concept of "supermodern" and tried to apply it in other areas - architecture and the "archeology of modernity". Finally, the author critically analyzes the concept, trying to find out its heuristic potential. From the author's point of view, the idea of supermodern does not stand up to criticism at the moment, as history has proved that Augé's intuitions, even if "preliminary", have not been justified in social, cultural and anthropological terms. The author also compares the concept of supermodern with that of postmodern, arguing that many of what is attributed to supermodern is actually immanently contained in postmodern theories, particularly in the cultural philosophy of the American Marxist Fredric Jameson.

Keywords: postmodern; post-postmodern; supermodern; social philosophy; culture; Marxism; hypermodern; anthropology; M. Augé

\section{REFERENCES}

Alexander, J. (2013) Smysly sotsial'noi zhizni: kul'tursotsiologiia. Moscow, Praksis Publ. 640 p. (In Russ.)

Anderson, P. (2011) Istoki postmoderna. Moscow, Territoriia budushchego Publ. 208 p. (In Russ.)

Augé, M. (1992) Non-lieux, introduction à une antbropologie de la surmodernité. Seuil, La Librairie du XXe siècle. p. 160.

De Certeau, M. (2013) Izobretenie povsednevnosti. St. Petersburg, European University at St. Petersburg Press. 330 p. (In Russ.)

Jameson, F. (2019) Postmodernizm, ili Kul'turnaia logika pozdnego kapitalizma. Moscow, Gaidar Institute Press. 808 p. (In Russ.)

Kuznetsov, V. (2017) Postsekuliarnyi vek neomoderna. Blizhnevostochnyi izvod. Gosudarstvo, religiia, tserkov'v Rossii i za rubezhom, no. 3, pp. 85-111. (In Russ.)

Augé, M. (2017) Ne-mesta. Vvedenie v antropologiiu gipermoderna. Moscow, Novoe literaturnoe obozrenie Publ. 136 p. (In Russ.)

Pavlov, A. V. (2018a) Obrazy sovremennosti v XXI veke: didzhimodernizm: retsenziia na knigu Alana Kirbi. Philosopby. Journal of the Higher School of Economics, vol. 2, no. 2, pp. 197-212. (In Russ.)

Pavlov, A. V. (2018b) Obrazy sovremennosti v XXI veke: avtomodernizm. Filosofskie nauki, no. 10, pp. 97-113. (In Russ.)

Pavlov, A. V. (2018c) Obrazy sovremennosti v XXI veke: metamodernizm. Logos, vol. 28, no. 6, pp. 1-19. (In Russ.)

Spiridonova, V. I. (2017) «Novaia sovremennost'» i traditsionnye tsennosti. Filosofskie nauki, no. 6, pp. 35-49. (In Russ.)

Hardt, M. and Negri, A. (2004) Imperiia. Moscow, Praksis Publ. 440 p. (In Russ.)

Cherniakhovskii, S. F. (2013) Traditsiia, modern i sverkhmodern. Fracture. Collection of Articles on the Justice of Traditions / ed. by A. Shchipkov. Moscow, PROBEL-2000. 176 p. Pp. 16-25. (In Russ.)

Adam, R. (2012) The Globalisation of Modern Architecture: The Impact of Politics, Economics and Social Change on Architecture and Urban Design Since 1990. Cambridge, Cambridge Scholars Publishing. 360 p.

Alexander, J. C. (2013) The Dark Side of Modernity. Cambridge, Polity. 187 p. 
Gonzalez-Ruibal, A. (2008) Time to Destroy. An Archaeology of Supermodernity. Current Antbropology, vol. 49, no. 2, pp. 247-279.

Gonzalez-Ruibal, A. (2014) Supermodernity and Archaeology. Encyclopaedia of Global Archaeology / ed. by Smith C. New York, Springer. 8015 p. Pp. 7125-7134.

Hutcheon, L. (2002) The Politics of Postmodernism. New York, London, Routledge. 222 p.

Ibelings, H. (1998) Supermodernism. Architecture in the Age of Globalization. Rotterdam, NAi Publishers. 160 p.

Kingwell, M. (2006) Meganarratives Of Supermodernism: The Spectre Of The Public Sphere. PhaenEx, no. 1 (spring/summer), pp. 197-229.

Kroker, A. and Kroker, M. (1988) Theses on the Disappearing Body in the Hyper-Modern Condition. Body Invaders. Sexuality and the Postmodern Condition / ed. by Kroker A., Kroker M. Houndmills, Basingstoke, Hampshire and London, Macmillan Education UK. 256 p. Pp. 20-34.

Lash, S. (1990) Sociology of Postmodernism. London, New York, Routledge. 300 p.

Lipovetsky, G. (2015) Time Against Time, or The Hypermodern Society. Supplanting the Postmodern. An Antbology of Writings on the Arts and Culture of the Early 21st Century / ed. by Rudrum D. and Stavris N. New York, London, New Delhi, Sydney, Bloomsbury Academic. 402 p. Pp. 191-208.

Reclaiming Archaeology. Beyond the Tropes of Modernity (2013) / ed. by Gonzalez-Ruibal A. London, New York, Routledge. 375 p.

Supplanting the Postmodern. An Anthology of Writings on the Arts and Culture of the Early 21st Century (2015) / ed. by Rudrum D. and Stavris N. New York, London, New Delhi, Sydney, Bloomsbury Academic. 400 p.

Submission date: 12.01.2019.

Павлов Александр Владимирович — кандидат юридических наук, ведущий научный сотрудник, руководитель сектора социальной философии Института философии РАН. Адрес: 109240, Россия, г. Москва, ул. Гончарная, д. 12, стр. 1. Тел.: +7 (495) 697-98-93. Эл. aдpec: ale-pavlov@ yandex.ru

Pavlov Aleksandr Vladimirovich, Candidate of Law, Leading Research Fellow, Head, Sector of Social Philosophy, RAS Institute of Philosophy. Postal address: 12, Bldg. 1, Goncharnaya St., Moscow, Russian Federation, 109240.Tel.: + 7 (495) 697-98-93. E-mail: ale-pavlov@yandex.ru 